\title{
AVALIAÇÃO DA RESISTÊNCIA À CORROSÃO LOCALIZADA DA LIGA DE ALUMÍNIO AA7050 - T851 EM DIFERENTES MEIOS.
}

\author{
L. F. REIS ${ }^{1}$, C. R. MARTINS ${ }^{1}$ e I. COSTA $^{2}$ \\ ${ }^{1}$ Universidade Federal de São Paulo, Instituto de Ciências Ambientais, Químicas e \\ Farmacêuticas, DEQ/UNIFESP, Rua São Nicolau, 210 - Centro, Diadema - SP- Brasil \\ 2 IPEN/CNEN-SP (CCTM), Av. Prof. Lineu Prestes, 2242 CEP 05508-000, São Paulo, SP. \\ E-mail para contato: lucasfelisbertodosreis@gmail.com
}

\begin{abstract}
RESUMO - O presente trabalho avaliou a resistência à corrosão localizada da liga AA7050-T851 e sua microestrutura para o uso na indústria aeronáutica. Investigou-se a resistência a corrosão em dois meios, $\mathrm{NaCl}(10 \mathrm{mM})$ e $\mathrm{NaCl}(1$ $\mathrm{mM})+\mathrm{Na}_{2} \mathrm{SO}_{4}(100 \mathrm{mM})$. Após $4 \mathrm{~h}$ de ensaio observou-se que a superfície da liga apresentava corrosão por pites em ambos os meios. Notou-se intenso ataque em meio de cloreto, enquanto grande parte da superfície permanecia intacta no meio de sulfato e cloreto. Houve dissolução seletiva de $\mathrm{Mg}$ e $\mathrm{Zn}$ e aumento de $\mathrm{Cu}$ nas áreas atacadas, o que enobreceu o potencial em meio de sulfato até se atingir potencial de pite Epite (cerca de $-0,2 \mathrm{VAg} / \mathrm{AgCl} / \mathrm{KClsat}$ ), estimado de curvas de polarização, passando-se a observar oscilações típicas de pite desde este potencial. Já no meio de cloreto, a liga se encontra no Epite desde os momentos iniciais de exposição ao meio. A liga AA7050 exibe grande suscetibilidade à corrosão por pites mesmo em meios com pequena contaminação de cloreto.
\end{abstract}

\section{INTRODUÇÃO}

As ligas de alumínio foram desenvolvidas por volta de 1906 para suprir a necessidade de um metal estrutural com baixa densidade e boa resistência mecânica. Dentre o vasto número de ligas de alumínio disponíveis, as que apresentam as melhores características para aplicação na indústria aeronáutica são as da série 7000. Esse tipo de liga é composto por uma porcentagem de zinco (1 a 8\%), além de pequenas frações de magnésio, o que proporciona ligas com melhor resistência mecânica e tratáveis termicamente. A liga AA7050 faz parte desse grupo de ligas de alta resistência mecânica e é especialmente interessante por preservar suas propriedades em espessuras muito finas (Totten et al, 2003; Bertoncello, 2014).

Assim como outros materiais estruturais, as ligas de alumínio estão sujeitas a corrosão e por isso necessitam de processos de controle de corrosão para preservar suas propriedades estruturais. Os tipos de corrosão mais comum nas ligas de alumínio são as corrosões localizadas. Estas se devem principalmente às heterogeneidades microestruturais intrínsecas às ligas de alumínio, mas também podem ser geradas por exposição a temperaturas acima da ambiente ou por processos mecânicos que ocorrem durante a fabricação da estrutura (Bertoncello, 2015). 
As ligas de alumínio de elevada resistência mecânica possuem grandes quantidades de partículas intermetálicas (IMs), as quais apresentam potencial eletroquímico diferente do da matriz. Esta combinação resulta na formação de pilhas de ação local e, por consequência, problemas de corrosão localizada. Além das partículas intermetálicas há também, nestas ligas, partículas submicrométricas. Caso estas partículas se precipitem nos contornos dos grãos, são formadas zonas de depleção em suas vizinhanças. Essas zonas de depleção, associadas com a baixa qualidade da película passiva na matriz vizinha a estas também geram micropilhas galvânicas (Bertoncello, 2014, Fioravanti, 2008; Thomas, 1991).

O presente trabalho visou caracterizar o comportamento frente à corrosão localizada da liga AA7050, como recebida, em dois meios, a saber, $\mathrm{NaCl}(10 \mathrm{mM})$ e $\mathrm{NaCl}(1 \mathrm{mM})+$ $\mathrm{Na} 2 \mathrm{SO} 4(100 \mathrm{mM})$.

\section{MATERIAIS E MÉTODOS}

\subsection{Preparo das Amostras}

Algumas amostras foram embutidas em baquelite para facilitar o manuseio; enquanto aquelas destinadas aos ensaios eletroquímicos, não foram submetidas a esse processo. As superfícies para exposição ao meio foram lixadas com lixas de $\mathrm{SiC}$ de granulometrias 320, 600 e $1200 \mu \mathrm{m}$. Em seguida, foi realizado o polimento das amostras com pasta de diamante 1 $\mu \mathrm{m}$, e lubrificação com etanol. Ao final dessa etapa, as amostras foram lavadas com água destilada e secadas sob fluxo de ar quente.

\subsection{Ensaios Eletroquímicos}

A célula eletroquímica adotada foi montada com dois eletrodos de platina (CE) curto circuitados, posicionados ao redor do eletrodo de trabalho (ET) para manter o campo elétrico uniforme em torno de uma área exposta de $1 \mathrm{~cm}^{2}$. Um disco de platina soldado em vidro foi conectado ao eletrodo de referência de $\mathrm{Ag} / \mathrm{AgCl}, \mathrm{KCl}$ por meio de um capacitor de $100 \mathrm{nF}$, para minimizar o deslocamento de fase (phase shift) e os ruídos do experimento.

\subsection{Ensaios de Imersão e Microscopia Eletrônica de Varredura}

As amostras embutidas e devidamente lixadas e polidas foram expostas aos eletrólitos por $12 \mathrm{~h}, 24 \mathrm{~h}, 56 \mathrm{~h}$ e $72 \mathrm{~h}$. Após esses períodos de exposição ao meio corrosivo, as superfícies expostas foram observadas por microscopia eletrônica de varredura (MEV), acoplado a microanalisador por espectroscopia de energia dispersiva (EDS).

\section{RESULTADOS E DISCUSSÕES}

\subsection{Caracterização Microestrutural}

As micrografias da Figura 1 mostram grãos de tamanhos muito diferentes, e áreas cujo ataque químico foi muito intenso e os grãos aparecem com coloração muito escura. $\mathrm{O}$ tamanho dos grãos das ligas de alumínio é muito influenciado por sua composição química. Normalmente, a diminuição do tamanho dos grãos é favorecida por elementos de liga comuns e impurezas como ferro, manganês, magnésio e cromo. 


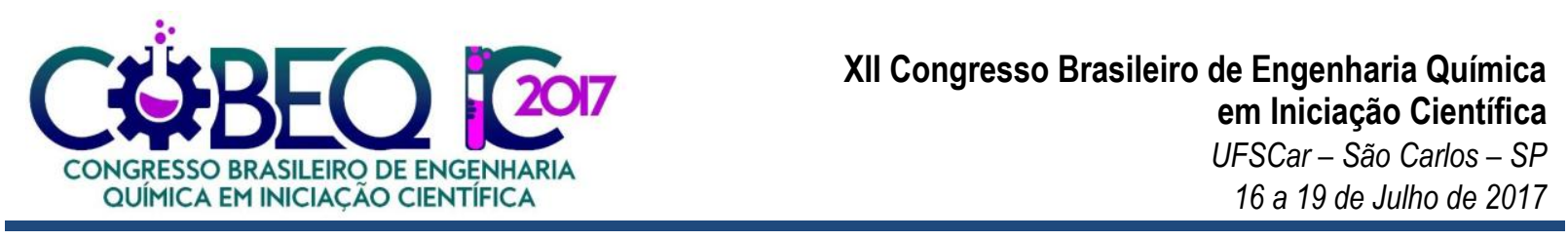

Figura 1 - Micrografia obtida por microscopia óptica da liga AA7050 em diferentes aumentos. Ataque: $2 \%$ HF e $25 \%$ HNO3 em água deionizada.
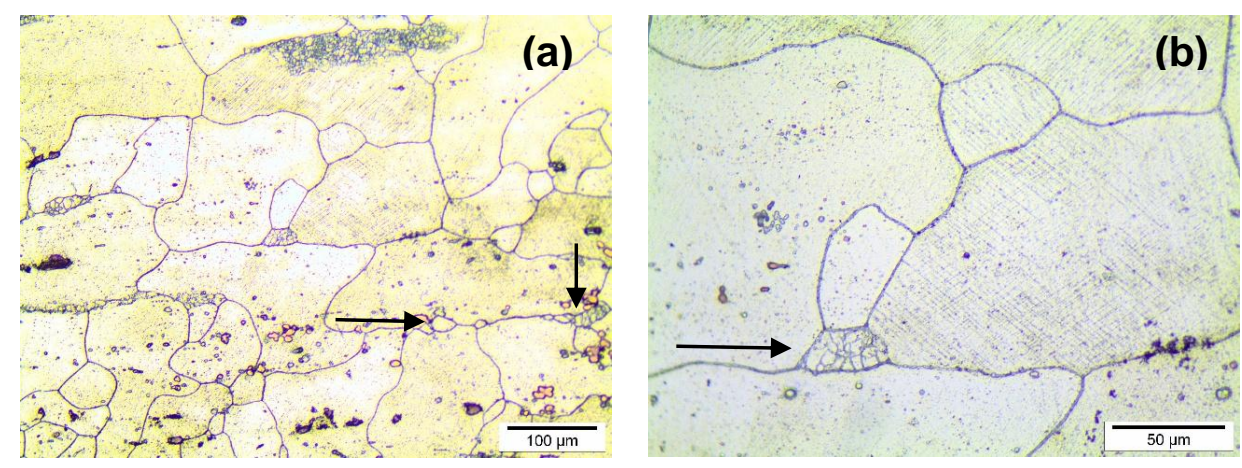

O crescimento dos grãos é produzido pelo aquecimento após a recristalização e pode acontecer de várias formas. $\mathrm{O}$ grão pode crescer gradual e uniformemente, o que é conhecido como crescimento normal de grão e é característico das ligas de alumínio. Esse tipo de crescimento elimina grãos com formas ou orientações desfavoráveis e ocorre quando existem pequenos grãos recristalizados, aquecimento generalizado e altas temperaturas. Esta característica é exibida nas Figuras 1 (a) e (b) em que as setas indicam o crescimento de grãos à custa de eliminação de pequenos grãos recristalizados.

\subsection{Ensaios de Imersão}

A Figura 2 apresenta a microscopia eletrônica de varredura obtida para a liga AA7050 nos diferentes tempos de imersão de 12 h, 24 h, 56 h e 72 h, respectivamente. Observa-se a presença de trincheiras de corrosão ao redor da maior parte dos IMs para todos os tempos de imersão. As trincheiras de corrosão são causadas pela dissolução preferencial dos elementos menos nobres e aparecem de maneira mais acentuada para tempos maiores de imersão

Figura 2: MEV das amostras em imersão de $\mathrm{NaCl}(10 \mathrm{mM})$ nos tempos de $12 \mathrm{~h}$ (a), $24 \mathrm{~h}$ (b), $56 \mathrm{~h}$ (c) e $72 \mathrm{~h}$ (d).
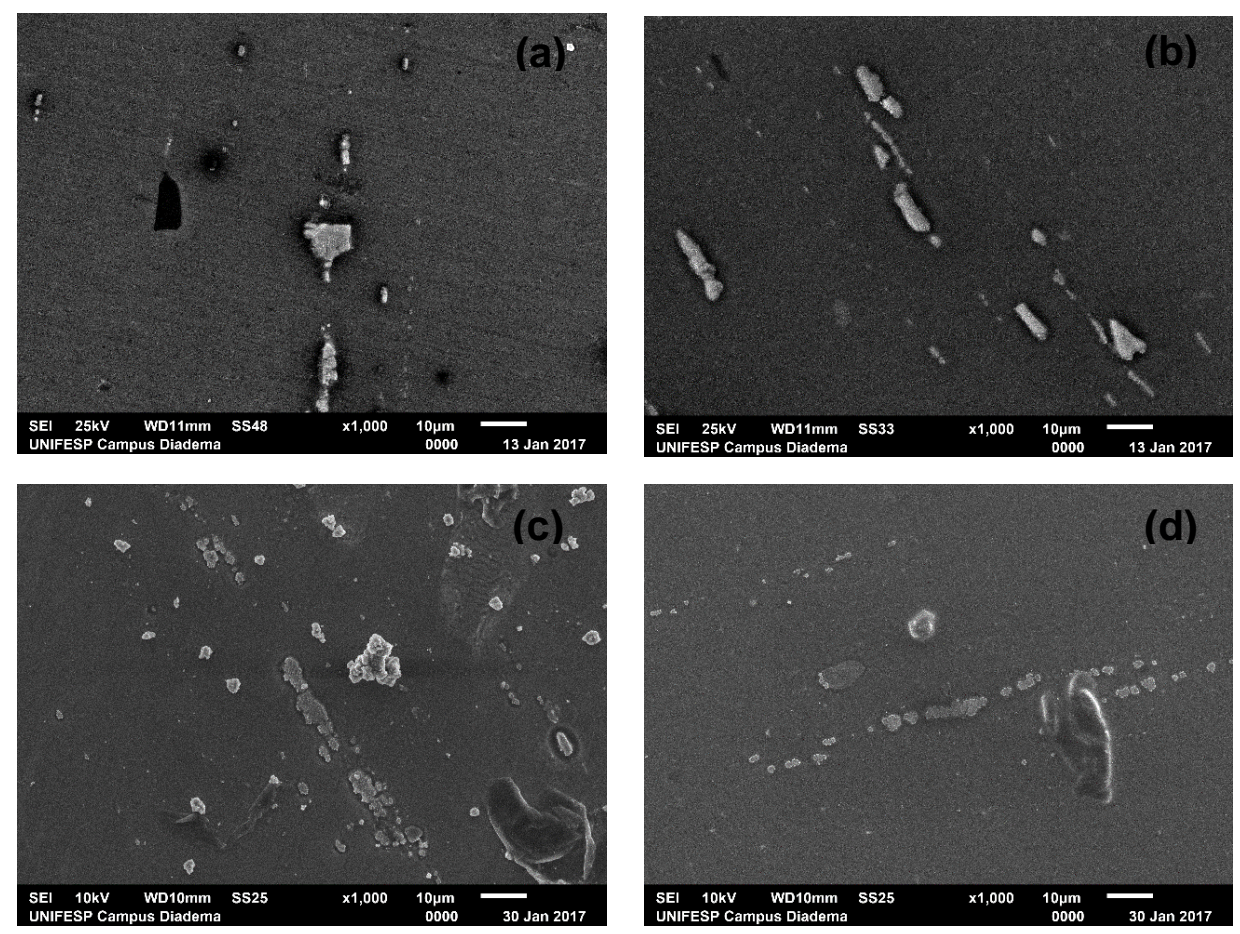
A composição dos precipitados foi avaliada por meio da técnica semiquantitativa de EDS. Em geral, os precipitados apresentaram menores quantidade de $\mathrm{Zn}, \mathrm{Mg}$ e $\mathrm{Al}$ e maiores quantidades de $\mathrm{Cu}, \mathrm{Fe}$ e $\mathrm{O}$, o que indica que a maior parte dos IMs são do tipo AlCuFe. Além disso, nota-se uma tendência a maiores frações de cobre nos precipitados de formato alongado como os da Figura 2b. Estudos indicam que a maior quantidade de $\mathrm{Cu}$ nos precipitados torna o potencial mais nobre, levando a corrosão da matriz.

\subsection{Ensaios Eletroquímicos}

A variação do potencial de circuito aberto da liga AA7050 durante 4 h de exposição aos dois eletrólitos utilizados é mostrada na Figura 3. Após 4 h de ensaio, o potencial de circuito aberto na solução (A), $\mathrm{NaCl} 10 \mathrm{mM}$, foi de cerca de $-0,54 \mathrm{~V}$, enquanto na solução (B), $\mathrm{NaCl}$ $(1 \mathrm{mM})$ e $\mathrm{Na}_{2} \mathrm{SO}_{4}(100 \mathrm{mM})$ foi de $-0,40 \mathrm{~V}$.

Figura 3: Monitoramento do potencial de circuito aberto para liga AA7050 após imersão de $4 \mathrm{~h}$ em diferentes eletrólitos.

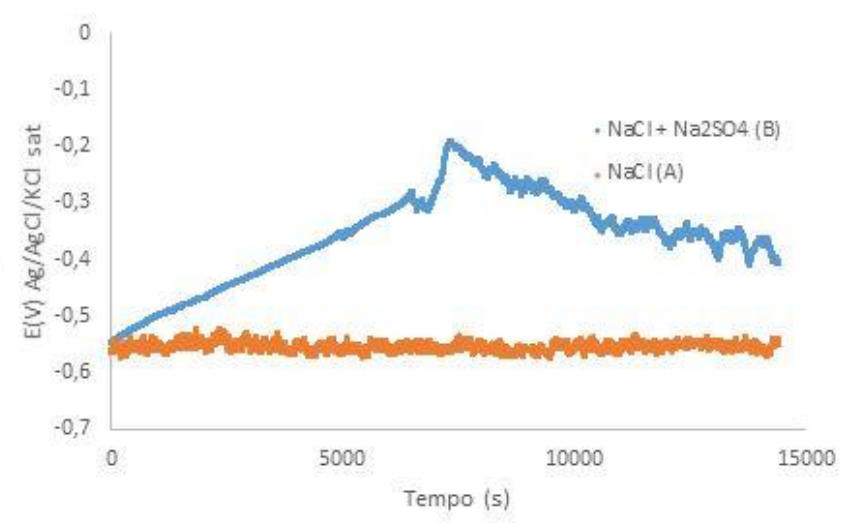

Para a solução B, constatou-se uma tendência ao aumento do potencial, o que pode ser causado pela adsorção de sulfato na superfície da liga que atua como um inibidor de corrosão da liga. Outra explicação para o aumento do potencial na solução contendo sulfato é a baixa agressividade no meio com baixo teor de cloreto e a possibilidade de crescimento de óxido de alumínio na superfície, particularmente sobre a matriz, aumentando a resistência à corrosão da superfície. A presença de pites foi comprovada por análise da superfície por microscopia óptica após os ensaios eletroquímicos, conforme ilustram as Figuras 4a e 4b.

Figura 4: Microscopia óptica da superfície da liga 7050 após 4 h de exposição em solução (a) $\mathrm{NaCl}$ ( $10 \mathrm{mM}$ ) e (b) solução de $\mathrm{NaCl}(1 \mathrm{mM})$ e $\mathrm{Na}_{2} \mathrm{SO}_{4}(100 \mathrm{mM})$.
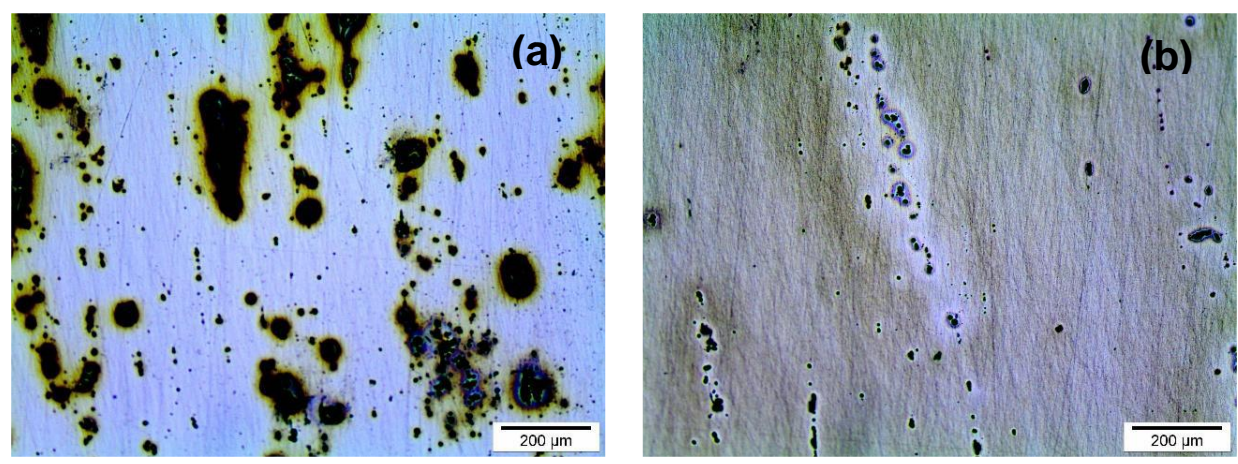
Os resultados mostram a elevada corrosividade da solução de cloreto à liga AA7050 e a preservação do aspecto não atacado de grande proporção desta liga após exposição à solução de sulfato e cloreto. Este resultado apoia a indicação de proteção da matriz da liga contra a corrosão também indicada pelo aumento de potencial com o tempo de exposição ao meio contendo sulfato.

A Figura 5 apresenta as curvas de polarização típicas para a liga AA7050 nos dois eletrólitos usados. A existência de dois picos na liga exposta ao meio contendo sulfato sugere situação de instabilidade desta neste meio corrosivo, alternando-se períodos onde prevalece a presença da camada passiva com períodos onde o ataque corrosivo a esta camada é predominante.

Figura 5: Curvas de polarização para a liga AA7050.

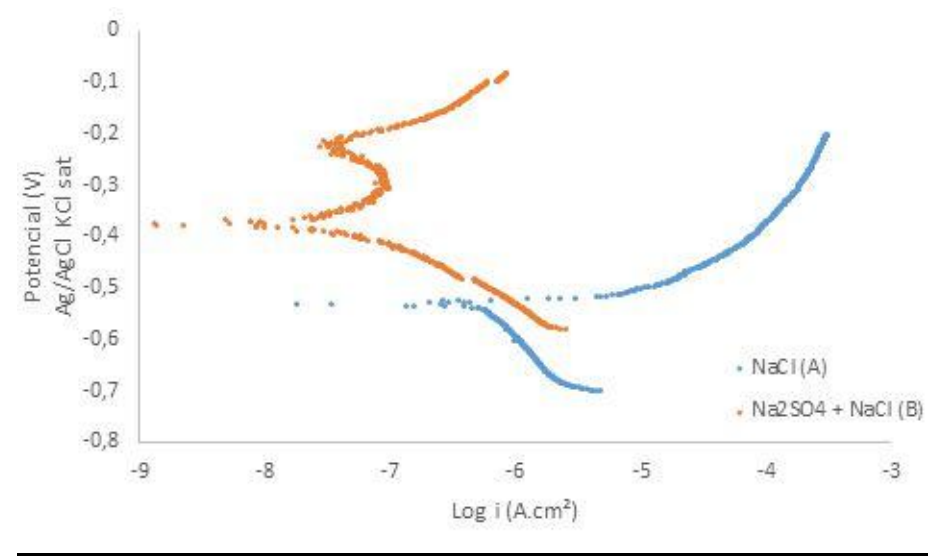

A comparação das curvas de polarização nos dois meios mostra que em meio de cloreto já ocorre intenso ataque corrosivo da liga AA7050 no potencial de corrosão, enquanto no meio contendo sulfato e cloreto em pequenas quantidades, a liga está passiva e a quebra do filme passivo ocorre em potenciais próximos a - $0,2 \mathrm{~V}$.

A Figura 6 mostra o diagrama de Nyquist obtido para a liga AA7050 nas duas soluções. A impedância associada ao meio de cloreto é significativamente inferior à do meio com sulfato e cloreto, conforme indicado pelos resultados obtidos pelas demais técnicas. Este resultado também é explicado pela observação da superfície após o ensaio (Figura 4). Em frequências mais baixas foi observado ruído devido à natureza evolutiva do sistema, o que pode ser atribuído a atividade elevada na superfície relacionada com a formação de pites.

Figura 6: Diagramas de Nyquist para a liga AA7050 exposta aos dois meios.

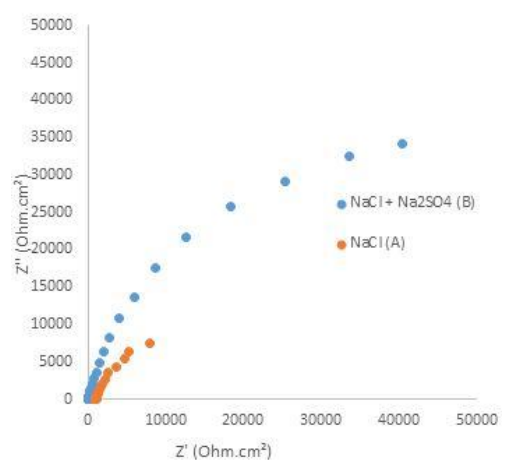




\section{CONCLUSÕES}

A liga AA7050 investigada apresentou suscetibilidade à corrosão por pites associada com a presença de precipitados/fases intermetálicas. Observou-se também ataque cristalográfico segundo direções preferenciais, ou seja, ataque em grãos com maior deformação, resultante de processos de fabricação/processamento. $\mathrm{O}$ meio de ensaio com 10 $\mathrm{mM}$ de $\mathrm{NaCl}$ mostrou-se muito agressivo à liga AA7050 que apresenta corrosão por pites já no potencial de circuito aberto. Em meio de $\mathrm{NaCl}(1 \mathrm{mM})$ e $\mathrm{Na}_{2} \mathrm{SO}_{4}(100 \mathrm{mM})$ a liga encontrase passiva, mas à medida que o potencial aumenta pela formação de óxido/adsorção de sulfato, a liga atinge o potencial de pite e o ataque localizado tem início.

\section{REFERÊNCIAS AGRADECIMENTOS}

[1] BERTONCELLO J.C.B, Avaliação da corrosão da junta dissimilar sobreposta das ligas AA7050-T76511 e AA2024-T3 soldadas por fricção linear com mistura. DISSERTAÇÃO. Universidade Federal do Rio Grande do sul, 93 p 2014.

[2] BERTONCELlO J.C.B; MANHABOSCO S.M.; Dick L.F.P. Corrosion study of the friction stir lap joint of AA7050-T76511 on AA2024-T3 using the scanning vibrating electrode technique. Corr. Sci.,94, p.359-367, 2015.

[3] FIORAVANTI A.S. Soldagem por FSW de ligas de alumínio Alclad AA2024-T2 e AA7075-T6. DISSERTAÇÃO. Universidade Federal do Rio Grande do Sul, 90 p. 2008.

[4] THOMAS W.M.; NICHOLAS E.D.; NEEDHA J.C.; MURCH M.G.; TEMPLE-SMITH P.; DAWES C.J. Friction stir butt welding. International Patent Aplliccation no. PCT/GB92/02203, December 1991.

[5] TOTTEN, G. E.; MACKENZIE, S.; DEKKER, M. Physical metallurgy and Process. Aluminium Handbook, v. 1, 2003.

\section{AGRADECIMENTOS}

FAPESP (Projeto Temático No. 2013/13235-6) 